\title{
Research on CMF Design and Charging Method in Smartphone - Centered on iPhone
}

\author{
Zhenjian Li, Xingchen Pan
}

HONGIK University, 04066; Hebei University of Science and Technology, 050018

Keywords: Smartphone; iPhone; CMF design; charging mode

\begin{abstract}
In recent years, as the "experience economy” develops continuously, user's emotional experience and personalized demand for smart phones are also increasing. CMF design has become an important factor for enterprises to innovate the design and enhance the core competitiveness of their products in the promotion of user experience. At the same time, the charging method plays an important role in the user experience presented by the materialization of smart phones, and has attracted extensive attention from the business circle. The reduction of the complicated operation and the improvement of the convenient and light experience in the process of use has been taken more and more seriously by designers and manufacturers. Therefore, teasing out the evolution of smart phones' CMF design and charging modes in this paper has important theoretical significance and practical value. The paper focuses on summarizing the evolution of the CMF design and charging mode of the iPhone, and their application in the design is illustrated through cases studies.
\end{abstract}

Along with the continuous development of the "experience economy", its differences from the traditional economy in many aspects and the homogenization trend of main technology of smart phones, consumers are not only satisfied with the use of products, but also have a higher pursuit of emotional experience and personalized needs of smart phones. Norman has explained in detail the importance of products' emotional experience to design in his book "Emotional Design" "1]. On the other hand, mobile phone have developed from the original communication terminals to today's multimedia service terminals. Accompanied with the growing popularity of large-screen smart phones, the power consumption of smart phones has continued to rise, but the development of battery technology has lagged behind the development of smart phones themselves. While enjoying the convenience of smart phones, users are also plagued by inefficient charging processes. The common point between the two lie in the emphasis of the consumers' "use" experience. Therefore, it is necessary to not only take the users' emotional experience and personalization as the focus of design, but also take the innovation of charging mode as an important experience element for consumers.

\section{The CMF Design of iPhone}

The design concept of CMF (color, material and finishing) was first proposed by European and American countries. It mainly refers to the process that the designer analyzes the cognition and trend of color, material and finishing and then redesigns the products on the basis of aesthetics, engineering, consumer psychology and many other interdisciplines and science and technology, and also refers to the R\&D activity that the designer meets consumers' demands for new products and requirements for experience through this process. It is an important part of the middle and later stage of product design. T (Trend) and E (Emotion) will be added to the future trend study of the product to form CMFTE. Under the current background of the "experience economy" trend, the development of smart phones' shape tends to be more and more homogenous, and CMF design is undoubtedly an important means for enterprises to enhance brand and product value. CMF design can show the consumers the value of the product and the different emotions of the product in the most intuitive way. It is not only an important bridge between designers and consumers, but also a channel connecting the designers' creativity and issues in product manufacturing, as well as the key to perfectly transforming a designer's design into a real product. This is the significance of CMF's 
design reality, and also the basic value that is widely valued by enterprises.

Since Apple's launch of iPhone and iPhone 3Gs in 2007 and 2009, the shape of smart phones has changed from a diversified to a straight, square and single shape, and gradually become homogenized. As a result, the detailed design of smart phones has received more and more attention from designers. Through the study on the color trend, the selection of new materials and unique finishing process, the different qualities and values of mobile phones have been comprehensively presented. Nowadays, CMF design plays an increasingly important role in the design of smart phones. After the target users are identified in the early stage of smart phone development, the target user group and the market segment will be analyzed to pave the way for the development of new products. Meanwhile, the CMF designer will analyze the development trend of color and materials and have a new exploration of the finishing through the fashion trends in the current year, and then combine with the user's emotional experience and personalized needs to determine the development direction for the design of new products.

In 2007, the launch of Apple's iPhone was a major event for the entire smart phone industry. As Steve Jobs said at the iPhone launch conference: "The emergence of the iPhone has changed the face of the phone forever." This is by no means accidental, not only because of the breakthrough in new technologies, but also because of the excellent CMF design. Apple's CMF design can be traced back to the new concept of iMac computer launched in 1997, which is one of Apple's most successful design cases. The iMac's bright and colorful color matching became the biggest highlight at that time. In the past, the traditional impression of computers was that it was a symbol of high technology and rationality, so computers are basically black, white and grey in color. However, Apple changed the computer with "a new dress", and showed more vitality in the selection of colors. Simply changing the color strategy is able to stand out among many competing productions, which is enough to illustrate the importance of CMF in product design. And Apple's innovation in CMF, especially on smart phones, have brought more diverse texture changes. So if iPhone redefines the smart phones, the iPhone 4 redefines the iPhone.

\begin{tabular}{|c|c|c|c|c|c|c|c|c|}
\hline \multicolumn{9}{|c|}{ iPhone CMF Design } \\
\hline \multirow[b]{2}{*}{ Information } & 2007 & 2008 & 2009 & 2010 & 2011 & 2012 & 2013 & 2013 \\
\hline & iPhone $2 \mathrm{G}$ & iPhone 3G & iPhone 3Gs & iPhone 4 & iPhone 4s & iPhone 5 & iPhone $5 \mathrm{c}$ & iPhone 5s \\
\hline \multicolumn{9}{|l|}{ Image } \\
\hline Feature & $\begin{array}{l}\text { capacitive to } \\
\text { uch screen }\end{array}$ & $\begin{array}{l}\text { Lead in } \\
\text { Apple Store }\end{array}$ & $\begin{array}{c}\text { Add: } \\
\text { fingerprint-proof fi } \\
\text { nish }\end{array}$ & $\begin{array}{c}\text { Add preposition: } \\
\text { FaceTime: apply } \\
\text { her own chip }\end{array}$ & $\begin{array}{c}\text { Add Siri } \\
\text { function of } \\
\text { voice assistant }\end{array}$ & $\begin{array}{c}\text { Support: } \\
\text { 4G-LTE Internet }\end{array}$ & $\begin{array}{l}\text { Colorful plastic } \\
\text { casing }\end{array}$ & $\begin{array}{l}\text { Add: Touch ID } \\
\text { fingerprint recog } \\
\text { nition }\end{array}$ \\
\hline $\begin{array}{c}\mathrm{C} \\
\text { (color) }\end{array}$ & $\begin{array}{l}\text { Back: } 4 / 5 \\
\text { silver-colour } \\
\text { ed,the rest: } \\
\text { black }\end{array}$ & Black \& white & Black \& white & Black \& white & Black \& white & $\begin{array}{l}\text { Black; white; } \\
\text { grey; golden }\end{array}$ & $\begin{array}{l}\text { White; yellow; } \\
\text { blue; green; pink }\end{array}$ & $\begin{array}{l}\text { Black; white; } \\
\text { grey; } \\
\text { champagne gol } \\
\text { den }\end{array}$ \\
\hline $\begin{array}{c}\mathrm{M} \\
\text { (material) }\end{array}$ & $\begin{array}{l}\text { Body: plastic } \\
\text { and } \\
\text { aluminum } \\
\text { alloy, middle } \\
\text { frame: } \\
\text { stainless ste } \\
\text { el }\end{array}$ & $\begin{array}{l}\text { Plastic casing, } \\
\text { liquid metal }\end{array}$ & $\begin{array}{l}\text { Plastic casing, } \\
\text { liquid metal }\end{array}$ & $\begin{array}{l}\text { liquid metalneed } \\
\text { le, stainless } \\
\text { steel border, } \\
\text { glass backboard }\end{array}$ & $\begin{array}{l}\text { liquid metalnee } \\
\text { dle, stainless } \\
\text { steel border, } \\
\text { glass } \\
\text { backboard }\end{array}$ & $\begin{array}{c}\text { Cover lens of } \\
\text { camera:sapphir } \\
\text { e,body: } \\
\text { anodised alumi } \\
\text { nium \& } \\
\text { glass-ceramic }\end{array}$ & Plastic casing & $\begin{array}{l}\text { Home sapphire } \\
\text { cover of home } \\
\text { board, body: } \\
\text { anodised alumin } \\
\text { ium \& } \\
\text { glass-ceramic }\end{array}$ \\
\hline $\begin{array}{c}\mathrm{F} \\
\text { (finishing) }\end{array}$ & $\begin{array}{l}\text { aluminum } \\
\text { alloy } \\
\text { backboard; } \\
\text { CNC } \\
\text { processing } \\
\text { technic }\end{array}$ & $\begin{array}{c}\text { Plastic } \\
\text { backboard, } \\
\text { technology: } \\
\text { Polished \& } \\
\text { polishing }\end{array}$ & $\begin{array}{c}\text { Plastic } \\
\text { backboard, } \\
\text { technology: } \\
\text { Polished \& } \\
\text { polishing }\end{array}$ & $\begin{array}{c}\text { CNC stainless } \\
\text { boarder }\end{array}$ & $\begin{array}{l}\text { CNC stainless } \\
\text { boarder }\end{array}$ & $\begin{array}{l}\text { Unibody } \\
\text { technology, } \\
\text { CNC process }\end{array}$ & $\begin{array}{l}\text { Hard coating } \\
\text { technology }\end{array}$ & $\begin{array}{c}\text { Unibody } \\
\text { technology, } \\
\text { shell: CNC } \\
\text { process }\end{array}$ \\
\hline
\end{tabular}

Fig.1

The iPhone 4/s uses a classic combination of black and white in color. In terms of material selection, the liquid metal is applied to the design of card pin for the first time. Its process embodies the distinctive characteristics of the use of CNC stainless frame design and the antenna partition 
injection molding, in which the injection molding strip is originated by Apple. Coupled with the design of front and rear glass panels, the entire iPhone 4/s looks both simple and generous, and guarantees good signals. The iPhone 5/s color is black, white, grey and gold. The gold is added for the first time, which makes the iPhone more diverse. The Home key and camera are made of sapphire materials to avoid camera scratches and resist fingerprints, while the phone body is made of anodized aluminum and ceramic glass. In particular, due to the application of the Unibody technology in the design of mobile phones, and the adoption of CNC processing technology for the whole casing of iPhone, not only the overall feeling and the metal texture of the phone becomes stronger, but also the mobile phones become thinner and thinner. By using this technology, not only Apple's minimalist style is manifested vividly, but the iPhone 5/s also becomes more refined through the design of frame, speaker hole, earphone hole and chamfering details of the charging port.

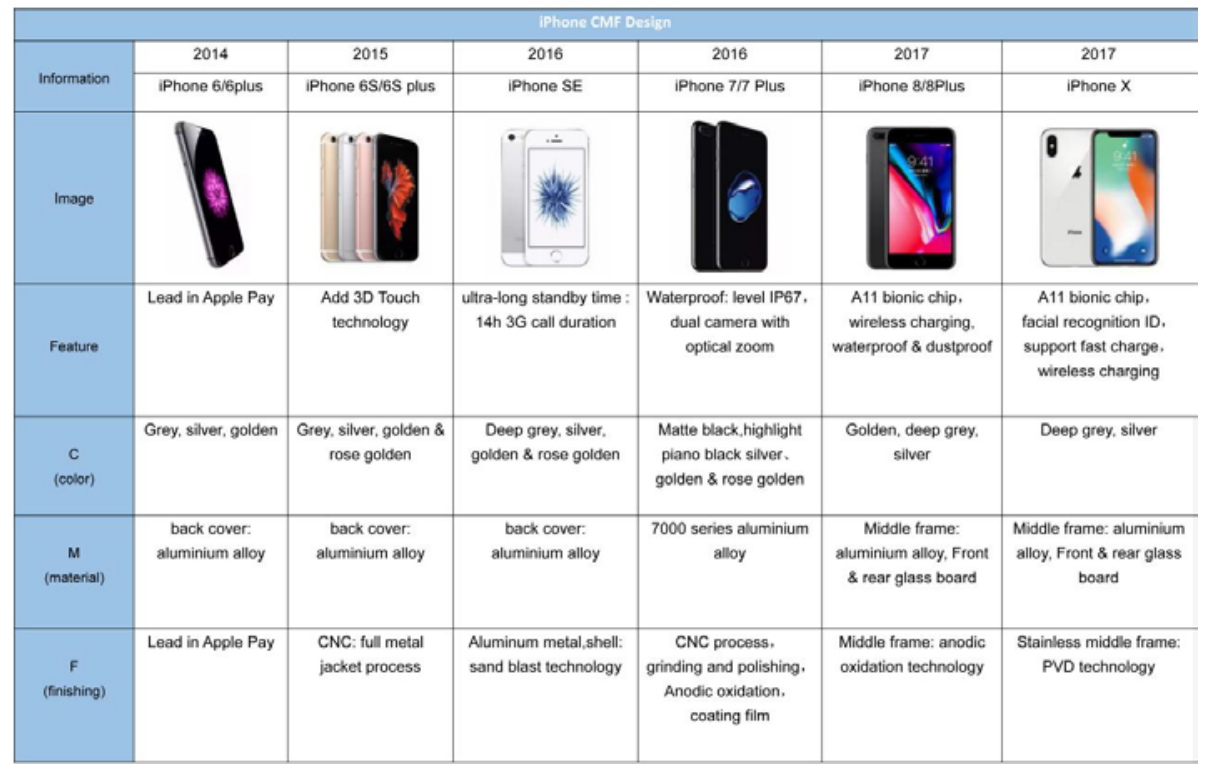

Fig.2

The iPhone 6/s body is silver, deep grey, gold and rose gold in color, of which, the iPhone 6s uses the rose gold for the first time and gives users a noble and gorgeous feeling. The glass cover-plate of the screen adopts the $2.5 \mathrm{D}$ glass, which makes the mobile phone look more rounded as a while. The phone body process adopts the CNC-processed all-metal casing, really realizing the Unibody design. In addition to the usual color matching of iPhone 6, the iPhone 7/Plus also adds two new colors, namely, the ordinary matte black and high-light piano black. At the same time, its body adopts the 7000 series of aluminum alloy materials and can be twice as hard as the iPhone 6/Plus. The high-light piano black is a attractive pint in the design of the iPhone 7/Plus, and the process of achieving this attractive point requires the use of anodizing and polishing processes that include 9 precision processes. The overall processing process is first CNC processing, then polishing it into a mirror surface, and then anodizing it for color, then polishing, and at last coating the surface. Such a perfect high-light piano black cannot be presented until all these processes are completed.

The iPhone8/Plus introduces a traditional color matching, namely, the gold, deep gray and silver. In response, instead of new materials different from the previous generation, the mobile phone's middle frame still uses aviation grade 7000 series of aluminum alloys. The front and rear panels are made of reinforced glass and surface-coated, which is effective in preventing oil stains and anti-fingerprints, and can also guarantee wireless charging function. The aluminum alloy frame is still anodized. The iPhone X is only available in deep gray and silver colors. The phone's middle frame is returned to stainless steel and uses the PVD process. The front and rear panels adopt the same glass materials as the iPhone 8 , and the multi-layer dyeing process and cladding materials are applied on the glass surface, which is also effective in preventing oil stains and anti-fingerprints. 


\section{Charging Method of iPhone}

There are two mainstream charging methods used in smart phones, namely, the wired charging and wireless charging, in which the wired charging includes regular charging and fast charging. The wired charging is also known as contact charging. Users need to use charging adapters, charging wires and other devices to complete the process of charging the phone, and this process plays an important role in the users' experience of the phone. In people's fast-paced life in modern society, it is well known that smart phones are increasingly becoming a must-have for people's communication and exchange. As people use their mobile phones for more and more time, they have more requirements for improving their charging efficiency and adopting the best charging methods. Therefore, the innovation of charging method is of special practical significance for improving user experience, reducing the complicated operation process, or saving social resources.

The innovation of iPhone is not only reflected in the design of CMF, but also in the continuous innovation of the technology. For example, in the technology innovation of the charging method, it considers both the overall design of the mobile phone and the user's experience. The launch of each generation of iPhone not only connects to the grasp of future technology development trends, but also connects to the grasp of enhancing the user's actual interactive experience. The charging method exists as an important form element that constitutes the user's actual use experience, not just a purely isolated technical element of smart phones.
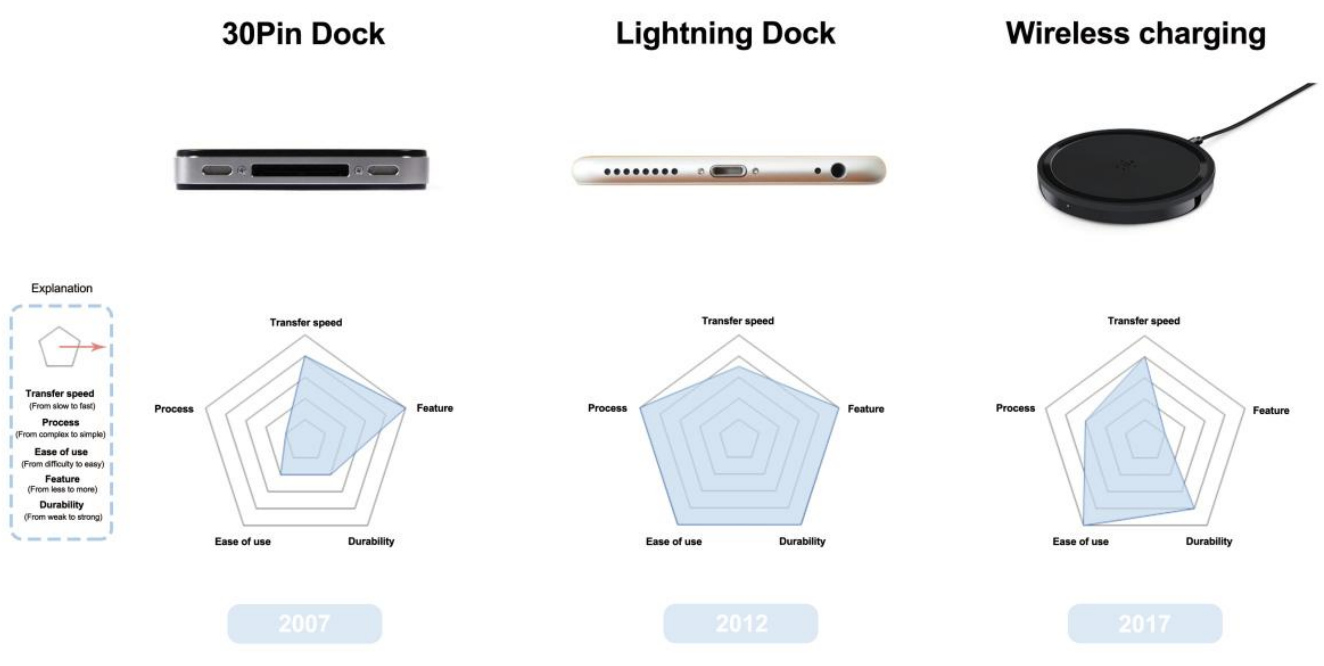

Fig.3

The 30Pin Dock has been used from iPhone2G to the iPhone4S, which lasted five generations of Apple phones. At that time, the mini USB equipped with mainstream mobile phone only provided the function of charging and data transmission, while the 30 Pin Dock charging interface has more features. Not only can it complete the function of charging and data transmission, but it can also perform many functions such as hi-fidelity audio output, playback control and photo synchronization. This not only represents Apple designers' continuous pursuit of increasing perfection, but also reflects Apple's far-sightedness to the future development direction of mobile phones. Although 30Pin Dock has a lot of extension functions, as the mobile phone continues to develop in a light and thin direction, especially when accessing in the opposite direction of the socket will cause irreparable damage, and the larger space occupied by the 30Pin Dock interface is easy to deposit large amounts of dust, the 30Pin Dock interface is thus difficult to escape the fate of 
being eliminated by the time.

The iPhone 5 uses the newly developed Lightning interface to solve the problem left by the 30Pin Dock interface, and has used this interface to this day. Since the Lightning interface has 8 pin contacts on both sides, not only it is unnecessary to distinguish between the front and the back when using the charging plug, but it can also reduces the volume of the plug by 5 times compared to the original and makes it more durable. The grooves of the Lightning connector on both sides are designed to tighten the connection between the plug and the socket. Both sides and the upper part of the plug are designed with round corners. The purpose of the rounded corners on both sides is to make it easier for the plug to be inserted into and press the inner spring. The rounded corner at the top of the connector is designed to touch the metal contact first when the plug is inserted in order to achieve the function of cleaning the contact point. The volume of Lightning interface is $80 \%$ smaller than that of the 30Pin Dock interface, while the related circuit complexity is also greatly reduced. Since the iPhone7, Apple has removed the $3.5 \mathrm{~mm}$ audio interfaces and integrated them into the Lightning interface, providing more space for the iPhone. It has also launched the wireless headset Air Pods, which, at the same time, heralds the advent of the wireless era.

As the wireless charging technology becomes increasingly mature, Apple iPhone finally ushered in the era of wireless charging. iPhone 8 and iPhone $\mathrm{X}$ support both wireless and wired charging. The built-in induction coil can be installed in the space of the original $3.5 \mathrm{~mm}$ audio interface, so that the overall thickness of the phone does not increase significantly. At the same time, in order to ensure a good wireless charging function, the aluminum alloy was replaced by a reinforced layer of glass for the back plate of the phone. Compared with wired charging, the biggest advantage of wireless charging lies in that it can provider more convenient charging experience. It allows users to remove the constraint brought by charging wires while avoiding the plugging and unplugging, making it a trend for the future development of mobile phone charging methods. However, the wireless charging technology applied to mobile phones, because of it technical limitations, requires the mobile phone to be placed in a fixed position before charging. As a result, the current wireless charging only solves the problem of complicated charging wire in the charging process.

In accordance with Apple's latest applied “wireless charging” patent, unlike the existing adsorption wireless charging technology, the "near-field magnetic resonance" technology is used to construct an effective charging area within 1 meter. If this technology can be used on smart phones, it will really get rid of the shackles imposed on mobile phones by charging wires, and the future will provide wider possibility and development space for the design of smart phones.

\section{References}

[1] Donald A.Norman.Emotional Design [M].New York: Basic Books, 2004.

[2] Donald A.Norman.The Design of Everyday Things [M].New York:Basic Books, 2013

[3] Jeremy Rifkin. The Third Industrial Revolution [M].Basingstoke:Palgrave MacMillan, 2013.

[4] Wu Qiong. Mobile Revolution: mobile phone design from functional to service [J]. Decoration (China):237, 2013.

[5] Information on https://www.apple.com/iphone/

[6] Information on https://en.wikipedia.org/wiki/Dock_connector

[7] Information on https://en.wikipedia.org/wiki/Lightning_(connector) 